\title{
Group Counseling for Medical Students with Drop-Out Experiences
}

\author{
Eun Kyung Kim', Sunyong Baek ${ }^{2,3}$, Jae Seok Woo, ${ }^{3,4}$ Sun $\mathrm{Ju} \mathrm{Im}^{3}$, Sun Hee $\mathrm{Lee}^{3}$, Beesung Kam³, \\ Sang Yeoup Lee ${ }^{3,5,6}$ and So Jung Yun ${ }^{7}$ \\ ${ }^{1}$ Pukyong National University, ${ }^{2}$ Department of Anatomy, ${ }^{3}$ Medical Education Unit, and ${ }^{4}$ Department of Physiology, \\ Pusan National University School of Medicine, ${ }^{5}$ Family Medicine Clinic and Research Institute of Convergence \\ of Biomedical Science and Technology, Pusan National University Yangsan Hospital, Yangsan, ${ }^{6}$ Medical Research \\ Institute, Pusan National University Hospital, and ${ }^{7}$ Center for Teaching and Learning, Pusan National University, \\ Busan, Korea
}

\section{의학유급생 집단상담 프로그램 시행경험}

부경대학교 ${ }^{1}$, 부산대학교 의학전문대학원 ${ }^{2}$ 해부학교실, ${ }^{3}$ 의학교육실, ${ }^{4}$ 생리학교실, ${ }^{5}$ 양산부산대학교병원 가정의학클리닉 및 의생명융합연구소, ${ }^{6}$ 부산대학교병원 의학연구소, ${ }^{7}$ 부산대학교 교수학습센터

\section{김은경 ${ }^{1}$, 백선용 ${ }^{2,3}$, 우재석,4, 임선주 ${ }^{3}$, 이선희 $^{3}$, 감비성 ${ }^{3}$, 이상엽 $^{3,5,6}$, 윤소정 ${ }^{7}$}

Purpose: The purpose of this research was to describe our group counseling methods for medical students with drop-out experiences.

Methods: Group counseling was offered to 11 medical students with drop-out experiences in their previous second semester. All subjects provided written informed consent before participating and completed a 2-day group counseling program using the Gestalt approach. The self-assertiveness training group counseling program consisted of 6 sessions, each of which lasted 90 minutes. Experience reports by participants after the program and data from semi-structured qualitative interviews were qualitatively analyzed. Results: Program participants reported that they were moderately satisfied with the program regarding its usefulness and helpfulness on self-awareness, understanding, and reminding them of attempts to change behavior. Most students showed heightened levels of sincerity perceptions and positive attitudes in every session. The results demonstrated significant changes in experience in self-esteem, self-recognition, and interpersonal relationships.

Conclusion: A group counseling program using the Gestalt approach could help medical students with drop-out experiences to adjust with 1 year their juniors, enhance their self-esteem, contribute to their psychological well-being, and prevent student re-failure through effective stress management and improved interpersonal relationships.

Key Words: Medical students, Group counseling, Drop-out

Received: October 10, 2012 • Revised: January 10, $2013 \bullet$ Accepted: January 26, 2013 Corresponding Author: Sang Yeoup Lee

Medical Education Unit, Pusan National University Medical School, 49 Busandaehak-ro, Yangsan 626-870, Korea

Tel: +82.51.510.8124 Fax: +82.51.510.8126 email: saylee@pnu.edu
Korean J Med Educ 2013 Mar; 25(1): 23-28. http://dx.doi.org/10.3946/kjme.2013.25.1.23 pISSN: 2005-727X eISSN: 2005-7288

(C) The Korean Society of Medical Education. All rights reserved. This is an open-access article distributed under the terms of the Creative Commons Attribution Non-Commercial License (http:// creativecommons.org/licenses/by-nc/3.0/), which permits unrestricted non-commercial use, distribution, and reproduction in any medium, provided the original work is properly cited. 


\section{서론}

미래의 의료계를 책임질 의학생들의 정신건강은 장차 사회 에 직접적인 영향을 미칠 수 있다는 점에서 중요한 의미가 있 다. 이전 연구에 의하면, 타 전공 학부 및 대학원생들에 비해 스트레스, 우울 등의 정신적 문제로 더 많은 어려움을 겪고 있 으며, 그 외에도 대인관계 어려움 및 자살과 같은 형태로 보고 되고 있어 그 심각성에 대한 인식이 점차 고조되고 있다[1,2]. 특히, 이전에 낮은 성적으로 유급된 경험이 있는 학생들의 경 우, 학교생활 부적응 경험 및 유급으로 인한 실패감과 좌절감 이 크다는 것을 감안하면 이들의 학교적응 및 정신건강을 위 한 적극적인 지원이나 체계가 시급하다.

게슈탈트 집단상담 프로그램은 자신이 겪고 있는 심리적 어려움을 자각하게 돕고 지금-여기에서 일어나는 자신의 감 정과 욕구를 민감하게 알아차리게 하고 집단 구성원과의 역 동 속에서 갈등을 다루는 상담기법이다. 이러한 집단상담 경 험은 상담하는 동안 카타르시스와 함께 통찰을 제공하며 이 후 스트레스 및 부적응 상황에서 보다 잘 대처하고 적응할 수 있는 내적인 힘이 되어주는 것으로 알려져 있다[3,4].

의학교육에서 유급제도는 모든 대학에서 시행되고 있으나, 문헌검색 결과 교육학적 측면에서 유급생 상담프로그램 운영 에 대한 효과분석과 대책에 대한 연구는 부족한 실정이었다. 국외의 경우는 학습부진과 관련된 다양한 연구들[5,6]이 수행 되었으나, 특히 국내의 경우 유급생 실태 및 예측요인에 대한 단편적인 연구일 뿐[7,8,9], 유급생을 대상으로 시행한 상담 프로그램의 운영 혹은 그 효과에 대한 연구는 전무하였다. 한 연구에 의하면, 약 $28 \%$ 가 유급의 경험이 있는 것으로 보고되 었고[7], 다른 의과대학/의학전문대학원의 경우에도 큰 차이 는 없을 것으로 판단된다. 의학전문대학원 체제로의 전환 여 부와 관계없이, 의학교육에 있어 유급생의 발생은 항상 있어 왔고, 지금까지는 개인의 문제이며, 따라서 학생 개개인이 극 복해야 할 과제로 그다지 관심의 대상이 아니었다. 저자가 속 한 학교에서도 교육과정 개편 이후 각 과목별 학업성취도 분 석을 시행하고 유급생에 대해 나름대로 지도교수 중심의 개 별지도를 하고 있고 원하는 학생은 학교에서 개별적으로 제 공하는 학습 및 심리상담 프로그램에 참여하도록 하고 있다.
하지만, 그 이용률은 매우 낮고, 실제로는 프로그램 자체보다 는 학교의 더욱 지대한 관심이 필요한 상황이었고, 최근 의과 대학인증평가의 평가 기준에까지 유급생 관리대책을 기술하 도록 되어 있어, 그 어느 때보다 의학교육에서 유급생의 학교 적응 프로그램과 유급 재발 방지의 중요성이 강조되고 있다. 한 연구에서 유급에 대한 대처방안을 제시하고는 있으나, 시 행 후의 효과에 대한 결과를 제시한 것은 아니었다[8]. 만약 어떤 프로그램을 통해 유급생들이 다음 학기에 학업에 더욱 잘 적응하고, 자존감이 향상되며 심리적으로 안정감을 회복 한다면 학업스트레스에 대해 보다 효율적으로 대처할 것이고 대인관계에서도 개선 효과를 가져다줄 것으로 기대된다.

앞서 언급하였듯이 유급생의 문제는 의학교육 현장에서 뿐 만 아니라 교육연구 분야에서 지금까지 지대한 관심의 대상 이 되어왔지만, 지금까지 유급생의 현황, 혹은 유급생의 특성 에 대한 단편적인 조사수준에 머물러 있었다. 이에, 저자 등은 유급생에 대한 개념, 원인, 특성, 선행 연구 검토 등의 관련 이론을 고찰하고, 과거 학교에서의 유급생 지도 실태를 바탕 으로 유급생에게 적합한 집단상담 프로그램 개발, 시행함으 로써 학교 현장에서의 유급생의 학교적응 및 유급 재발방지 에 도움을 주고자 하였다.

\section{대상 및 방법}

\section{1. 조사 대상}

부산대학교 의학전문대학원 재학생 중 2009년 2학기 해당 학년의 과정에서 유급한 후 2010년 2학기에 복학하는 총 17 명 중에 집단상담 프로그램에 참여한 11명(남학생 9명, 여학 생 2명)의 복학생을 대상으로 시행하였다. 평균 29.9세(최저 25세, 최소 32세)이고, 6 회 유급 경험을 가진 학생 1 명, 2회 유급 경험을 가진 학생 1 명을 제외하고는 모두 1 회 유급생이 었다.

\section{2. 집단상담 프로그램 내용}

모든 조사 대상자에게 프로그램의 목적을 설명하여 동의를 구한 후 1 박 2 일간의 집단상담 프로그램을 시행하였다. 첫째 
날은 산장에 도착한 후 저녁식사를 하고, 저녁 7시부터 11시 까지 집단상담 1 회기, 2 회기를 시행하였다. 이후 취침을 하고, 둘째 날에는 아침 식사를 함께 하고, 오전 8시 30분부터 낮 12 시까지 집단상담 3,4 회기, 점심 이후 오후 1 시부터 오후 6 시까지 집단상담 5,6 회기로 총 6 회기의 집단상담을 시행하고 1 박 2일의 집단상담 프로그램을 종료하였다.

집단상담 프로그램의 각 회기 내용은 다음과 같다.

1 회기(만남과 라포 형성)는 프로그램 전반에 대한 소개, 서 로 간의 소개를 통한 친밀감 형성 및 참여 동기 고취를 목표로 두었다. 프로그램에 대한 목적과 내용을 소개하고, 서약서를 작성하며, 이어 들어가는 활동으로 별칭을 지어보고 자기를 소개하도록 하였다.

2회기(나 들여다보기)는 자기의 욕구와 감정을 자각하고 이해하는 것을 목표로 설정하였다. 자기를 이해하는 작업으 로 “나는 누구일까요?”라는 질문으로 현재의 심정을 자각하고 도화지와 크레파스를 사용하여 표현해보게 하였고, 이어 문 장완성작업을 통해 욕구 및 감정을 심층적으로 자각하고 이 해하도록 하였다.

3회기(나 자각하기)는 나의 몸과 마음을 알아차리고 표현 하는 것을 목표로 두었다. 자신이 억압하고 있던 좌절감 및 분 노감을 자각하고 표현해보도록 하고, 부정적 감정을 명료하 게 표현하고 해소해보면서 집단 내에서 수용 받는 경험을 하 는 시간을 가졌다.

4 회기(내 모습 찾기)는 나의 참 모습을 이해하는 것을 목표 로 두었다. 자신이 보여주고 싶은 면과 보여주고 싶지 않은 면
이 무엇인지 도화지와 크레파스를 이용한 작업을 통해 자각 하고, 1 인 2역이라는 사이코드라마를 통해 다양한 시각에서 내 모습 바라보면서, 부정적인 자아개념의 자각과 행동패턴 간의 연결성을 통찰한 후, 부정적인 자아개념의 수정과 함께 통합을 이루고 행동패턴의 변화가 가능함을 깨닫도록 하였다.

5 회기(미래의 나)는 자신의 욕구와 기대하는 목표를 명료 화하는 것을 목표로 시행하였다. 도화지와 크레파스를 사용 하여 자신의 미래 모습을 명확히 그려보게 한 다음, 미래 모습 을 이루기 위한 목표와 실천방향을 점검하는 시간을 가졌다.

6회기(마무리 및 이별)는 지금까지의 내용을 나누고 격려 하는 시간이다. 집단상담 프로그램에 참여한 경험을 나누고, 개개인을 위한 장점세례를 통해 서로 격려하며, 대안을 탐색 하고 그것을 현실적으로 적용할 수 있는 방안을 강구하면서 이별의식을 시행하였다.

\section{3. 집단상담 프로그램 시행 후 설문과 분석}

설문지는 크게 5점 Likert scale (매우 그렇다, 5점; 그렇 다, 4점; 보통이다, 3점; 아니다, 2점; 매우 아니다, 1점)로 구 성된 객관식 10문항(Table 1)과 주관식 5문항으로 구분하였 다. 주관식 문항으로는 1) 프로그램 종료 후의 기분, 2) 프로 그램 전, 후의 개인적 차이, 3) 가장 좋았던 프로그램, 4) 이번 프로그램을 통해 도움이 된 점 및 5) 프로그램에 대해 아쉬운 점과 바라는 점으로 선정하였다. 주관식의 각 항목마다 자유 롭게 기술하도록 하였다. 수집된 객관식 문항마다 평균과 표 준편차를 구하였다.

Table 1. Feedback from a Questionnaire after Group Counseling

\begin{tabular}{lc}
\hline \multicolumn{1}{c}{ Contents } & Mean \pm SD \\
\hline This program was helpful to me & $3.07 \pm 1.28$ \\
I was satisfied with this program & $2.73 \pm 1.10$ \\
The program schedule was adequate & $2.27 \pm 0.96$ \\
The place and atmosphere contributed the effectiveness of the program & $3.20 \pm 1.15$ \\
The counselor was prepared enough at the program and tried to help & $4.40 \pm 0.63$ \\
I participated actively in the program & $3.73 \pm 0.80$ \\
I participated sincerely and honestly in the program & $3.80 \pm 1.08$ \\
Group counseling was more helpful than individual counseling & $3.20 \pm 1.27$ \\
I would like to take part in a follow-up program & $1.87 \pm 1.13$ \\
I would definitely recommend this program to my colleagues & $3.07 \pm 1.58$ \\
\hline
\end{tabular}

SD: Standard deviation. 


\section{결과}

\section{1. 객관식 설문}

설문지 분석 결과 프로그램의 유익성과 만족도는 보통 수 준이었으나 1박 2일간의 프로그램 소요시간에 대해서는 다소 길다고 응답하였다. 프로그램 장소와 분위기에 대한 효과, 개 인상담보다는 집단상담의 우월성에 대해서는 보통 수준이었 다. 집단상담자의 준비, 도우려는 의도에 대해서는 매우 높게 받아들였고, 학생 대부분이 프로그램에 능동적이고 진지하며 솔직하게 참여하는 편이었다. 반면에 후속 프로그램에 참여 할 의사는 낮았으나, 대체적으로 이번 프로그램을 동료에게 추천하고 싶어 하였다(Table 1).

\section{2. 주관식 설문}

\section{1) 프로그램 종료 후의 감정}

"많은 도움이 되었습니다. 감사합니다.", "조금 후련해요.", "시원합니다. 후련한 마음이고 앞으로 잘할 수 있다는 자신감 이 생겼어요.", “좀 지겹지만 끝내고 나니 홀가분해요. 행복합 니다. 처음 생각했던 것 보다 그렇게 어렵지 않게 잘 끝나 홀 가분합니다.", “후련한 것도 있고 좀 더 실속 있게 프로그램이 준비 안 된 것에 아쉬움이 남습니다.", "장기적으로 도움이 되 길 바랍니다.”라는 긍정적인 기분을 표현한 학생도 있었으나, “그저 그렇다.", "약간 우울하였고, 잊었던 기억이 다시 떠올랐 습니다.”, “별로 안 좋습니다.", “음. 그냥 애매합니다.”라는 개 인적으로 유익하지 못하였다는 기분을 표현한 학생도 있었다. 1 명은 “충분한 고지 없이 참석하여 하는 동안 별 필요성을 못 느끼며 마친 현재도 필요성에 대한 의문이 들며 죄인이 된 듯 한 기분입니다.”라고 매우 부정적인 표현을 하였다.

2) 프로그램을 하기 전과 하고 난 후 생각, 감정 및 관계 등에서 달라진 점

5 명의 학생은 "나름 의지를 다졌었는데 더 굳어진 듯합니 다.", "자신감과 의지력이 상승했습니다.", "좀 더 내 마음이 개 방된 것 같습니다." "좀 더 나 자신을 공개적으로 정리하는 계 기가 되었습니다.”, “재충전" "조금 더 자신감을 찾게 되었습 니다.", “좋아졌습니다.”, "감정을 공유한 몇몇에게는 도움을
받은 것 같습니다만 전체적으로 친해지고 공유한 것은 아닌 것 같습니다.", "기운이 넘치고 의욕이 넘쳤던 것들이 나의 잘 못을 되새기며 기분이 다운되었습니다.”라고 긍정적인 표현 을 하였으나, 나머지 6 명은 달라진 게 별로 없다고 하였다.

\section{3) 가장 좋았던 세부 프로그램과 그 이유}

학생들은 " 1 인 2역 연극. 나의 잘못된 점을 솔직하게 연기 할 수 있었습니다.", "좋았던 기억 나빴던 기억말하기. 생각을 말로 표현하는 것과 남에게 피드백 받는 것이 좋았습니다.”, "감각 알아차리기", "역할극", "자신의 문제를 스스로 적어보는 것", “좋았던 기억 나빴던 기억 공유하기", "자신의 장점과 단 점을 동료와 공유하기", "나에게 쓰는 편지. 스스로를 다시 돌 아보게 되었습니다.”, “조 이루어서 장단점 말하기”, “서로의 문제를 나눌 수 있었던 것”, “서로 간의 고민 상담", "둘째 날 오전 프로그램이 참여도가 좋았던 것 같습니다." 등 다양한 활 동을 좋은 경험으로 여겼다.

\section{4) 프로그램을 통해 도움이 된 점}

학생들은 프로그램의 목적대로 자아성찰과 반성, 자신감 개선 또는 회복, 스스로를 잘 다루기, 감정에 더 솔직해지기, 이해심 증가, 타협의 기술, 관계 개선, 개선점 확인, 개선하고 자 하는 의지 확인, 다짐, 다시는 유급되지 않겠다는 각오, 인 내심과 의지 향상 및 비슷한 경험을 한 동료들을 알게 되고 서로 간에 감정과 생각을 나눌 수 있었던 점 등이 이번 집단상 담 프로그램을 통해 도움을 얻게 되었다고 하였다.

\section{5) 프로그램에 대한 아쉬운 점, 바라는 점}

"비밀유지가 되는지 의문이 들어 적극적으로 참여하기 힘 들었습니다.", "기본적으로 불만이 쌍인 감정에서는 상담도 효 과가 없을 것 같습니다.", "학기 도중보다는 방학을 이용했으 면 합니다.", "이번 프로그램의 2/3 수준으로 상담은 줄이고 중간에 쉬는 시간을 주었더라면 스트레스 해소에 도움이 되 었을 듯합니다.", "상시적으로 학교에서 상담할 수 있는 프로 그램이 있었으면 합니다.", "장소가 나쁘지는 않은데 자리가 조금 불편했습니다.", "사전에 보다 프로그램 내용에 대한 충 분한 설명이 있었으면 합니다.”라고 지적한 반면 1명은 “다 좋 았습니다."라고 하였고 다른 1 명은 “프로그램 이후 보다 더 우 울해졌습니다."라고 하였다. 


\section{고찰}

게슈탈트 상담이론에 바탕을 둔 집단상담 프로그램은 상담 을 통해 진정한 자신을 알고 자신의 부정적인 면을 직면하고 수용함으로써, 긍정적 자기 개념 및 자존감을 향상시키는 효 과가 있다. 자아정체성이 분명해지면 상담의 목표가 보다 효 과적으로 달성될 수 있고, 주변 환경에 적절히 대처할 수 있는 창조적인 능력을 소유하게 된다는 전제에서 출발한다. 즉, 타 인의 욕구 충족을 방해하지 않으면서 감정, 지각, 사고 및 신 체가 모두 통합된 기능을 발휘하여 자신의 욕구를 바람직한 방법으로 충족할 수 있음을 직접 경험할 수 있게 된다. 또한, 효율적인 의사소통 및 갈등 해결 방법도 자연스럽게 습득할 수 있게 된다[3,4]. 이러한 집단상담 경험은 상담하는 동안 카 타르시스와 함께 통찰을 제공하며 이후 스트레스 및 부적응 상황에서 보다 잘 대처하고 적응할 수 있는 내적 힘을 길러준 다. 따라서 집단상담에 참여한 경험은 스트레스 상황에 부딪 칠 때마다 잘 이겨낼 수 있는 장기적이고 지속적인 효과가 있 을 것으로 기대한다[10,11].

저자 등은 처음으로 유급생을 대상으로 학교 적응 및 자신 감을 증진시키고, 심리적 안정감 회복을 위해 집단상담을 계 획하여 실시하였다. 집단상담 프로그램을 실시한 후 참여한 학생들의 집단상담가에 대한 평가는 평균 4.4점으로 매우 높 았다. 또한 대체적으로 프로그램이 도움이 되었고, 자신이 적 극적이고 진솔하게 참여하였다고 평가하였다. 하지만, 세부적 으로는 집단상담가가 다른 집단에서 시행한 경험에 비해 이 번 프로그램을 다소 이끌기 힘들었고 일부 학생은 참여도가 매우 낮았다고 사후 보고하였던 것으로 볼 때, 향후에는 참여 대상학생에게 프로그램의 취지를 충분히 설명하고, 참여하지 않더라도 학교로부터의 불이익은 없는 것을 인지시킨 후 학 생이 충분히 공감하고 자의에게 의해 참석이 되도록 되새겨 볼 필요가 있다.

흥미로운 것은 이번 프로그램을 다른 동료 학생들에게 권 유하고 싶다는 평가는 평균 3.07 로 보통 이상이었으나 후속 프로그램에 참여하겠다는 평가는 1.87 로 점수가 가장 낮았던 것을 볼 때, 의학생에 있어 집단상담은 아직 익숙지 않은 상담 으로 여겨지는 것 같다. 비록 참여 전에는 집단상담 프로그램
의 목적과 진행방법에 대해 제대로 인지하지 못했다고 하더 라도, 경험 후에는 이러한 집단상담 프로그램이 동료 학생에 게 어느 정도 권할 정도라고는 여긴 것으로 볼 때 절반의 성공 은 했던 것 같다. 반면, 유급생에 국한된 프로그램이었기 때문 에 후속프로그램에 참여하지 않겠다는 다시는 유급을 경험하 지 않겠다는 의지의 표현일 수 있겠다. 특히 2학년에 복학할 남학생의 경우, 이 기간에 2학년 전체 모임과 중복되어 거기 에 참여하지 못한 아쉬움이 컸다. 이들은 다른 참여 학생과 달 리, 동료 유급생의 자괴감을 부추겼으며, 집단상담에 적극 참 여하기보다는 오히려 상담 분위기를 흐려 놓기 쉬웠다. 집단 상담에 참여하는 개개인의 적극적이고 진솔한 참여가 상담 효과의 성패를 좌우하는 집단상담의 특성상 향후 이러한 프 로그램을 계획하고 수행 할 때에는 상담의 목적 및 프로그램 에 대해 보다 충분히 세부적으로 설명을 하고 참여에 적극 동 의한 학생에 국한해서 실시하는 것이 좋겠다. 마지못해 참석 한 사람에게서 상담 효과는 기대하기 어려우므로 이후에는 비록 참여 학생의 수가 적더라도 상담의 효과적 측면을 고려 할 필요가 있다. 또한 학기 중에 프로그램을 시행함으로써 학 생들의 어려움이 컸는데, 우선 금요일 수업을 마친 후 출발하 여 그날 오후 11 시까지 프로그램을 진행하다보니 피로감이 컸으며 다음 주에 있을 발표나 시험 걱정 등으로 상담에 몰입 하기 힘들어 하였다. 향후에는 개강 직전 실시를 고려할 필요 가 있다. 그럼에도 불구하고 참여한 대부분의 학생들은 상담 을 통해 도움을 받았다고 느꼈으며 특히 자신감을 회복하고 자신에 대해 되돌아보고, 같은 어려움을 겪는 동료들의 이야 기를 들으며 위로도 받고 다시는 유급되지 않겠다는 의지도 확인하는 좋은 계기가 되었다. 또한 학생들은 유급이 되기 전 에 학기 중에 학업 스트레스가 높을 때 도움을 받고 싶어 하였 으며 학기 중에 상시적으로 이러한 프로그램이 활성화 되어 시행되길 희망하였다.

연구 제한점으로는 이 연구가 일개 학교 11 명의 유급을 경 험한 의학생에 국한되어 집단상담 프로그램 시행한 후 조사 된 것으로 일반화에 한계가 있으므로 앞으로 여러 의과대학 및 의학전문대학원 학생을 대상으로 연구가 진행될 필요가 있다. 하지만, 유급생이 일개 학교에 많은 것도 교육학적 측면 에서 바람직하지 않고, 타 학교와 공동으로 진행하는 것도 학 생들의 동의를 구하기가 어려울 수 있어 연구 대상 수를 확대 
하여 연구를 수행하는 것도 수월하지는 않을 것으로 예상된 다. 이번 연구 결과 집단상담 프로그램은 유급생의 학교적응 력 증진과 자존감 향상을 도와줄 수 있고, 심리적 안정에 기여 할 뿐 아니라, 학업스트레스에 대한 효율적 대처와 대인관계 개선 등을 통해 유급의 재발 방지가 가능하도록 해 줄 것으로 기대된다. 후속 연구가 지속되어야겠으나, 1 년 후 다시 유급 하였는지를 조사한 결과, 집단상담에 참여한 경우는 11 명 중 에 2명(18.2\%)으로, 참여하지 않은 경우인 4명 중에 1 명 (25.0\%)에 비해 그 비율이 낮았다. 이는 유급이 원인이 매우 다양하기 때문에 어느 특정요소로 단정할 수는 없으나, 집단 상담의 효과가 일부 있었을 것으로 추정한다. 프로그램을 통 한 효과를 평가하는 것이므로, 프로그램 시행 전과 후의 설문 에 대한 반응을 비교하는 것이 합당하지만, 단지 "프로그램을 하기 전과 하고 난 후 생각, 감정 및 관계 등에서 달라진 점이 있다면 무엇인지?"를 묻는 1 가지 항목으로 이를 대체하였다 는 점에서 프로그램 시행 전후의 비교가 다소 부족했습니다. 향후에는 유급생 뿐 아니라 학업성취도가 낮고 학업에 어려 움이 있어 유급의 위험이 높은 학생들을 대상으로 사전, 사후 적절히 집단상담 프로그램을 시행하여 그 효과를 검증하고 지속적으로 개선할 필요가 있을 것이다.

Acknowledgements: None.

Funding: This study was supported by Medical Research Institute Grant (2012-22), Pusan National University Hospital.

Conflicts of interest: None.

\section{REFERENCES}

I. Hur Y, Lee KH. Analysis of medical students' enneagram personality types, stress, and developmental level. Korean J Med Educ 2011; 23: 175-184.

2. Yune SJ, Park KH, Chung WJ, Lee SY. The effects of attribution tendencies, academic stress, and coping efficacy on academic adjustment of medical students. Korean J Med Educ 2011; 23: 167-174.

3. Lee HK. Group psychotherapy: theory and practice. J Korean Neuropsychiatr Assoc 2002; 41: 189-200.

4. Rosenfeld E. An oral history of Gestalt therapy: part I. A conversation with Laura Perls. Gestalt J 1978; 1: 8-31.

5. Arulampalam W, Naylor RA, Smith JP. Dropping out of medical school in the UK: explaining the changes over ten years. Med Educ 2007; 41: 385-394.

6. Niemi PM, Vainiomäki PT. Medical students' distress: quality, continuity and gender differences during a sixyear medical programme. Med Teach 2006; 28: 136-141.

7. Park J, Kang MG, Ryu SY, You JW, Moon KR. Predictors of failure in medical students. Korean J Med Educ 2009; 21: 143-151.

8. Kim SH, Jeon WT. The failure experiences of medical school students: a qualitative study. Korean J Med Educ 2008; 20: 351-362.

9. Han ER, Chung EK, Oh SA, Chay KO, Woo YJ. Medical students' failure experiences and their related factors. Korean J Med Educ 2012; 24: 233-240.

10. Song SW, Yon MH. A qualitative study of college students' change experiences of self-assertiveness improvement group counseling. Korea J Couns 2008; 9: 16411663.

11. Seo YJ. Analysis of group-counseling studies for resolving emotional and social problems of students with learning disabilities. Korea J Learn Disabil 2012; 9: 187-214. 